\title{
U.S. Geological Survey Distribution of European Space Agency's Sentinel-2 Data
}

A partnership established between the European Space Agency (ESA) and the U.S. Geological Survey (USGS) allows for USGS storage and redistribution of images acquired by the MultiSpectral Instrument (MSI) on the European Union's Sentinel-2

satellite mission. The MSI data are acquired from a pair of satellites, Sentinel-2A and Sentinel2B, which are part of a larger set of ESA missions focusing on different aspects of Earth observation. The primary purpose of the Sentinel-2 series is to collect multispectral imagery over the Earth's land surfaces, large islands, and inland and coastal waters. Sentinel-2A was launched in 2015 and Sentinel2B launched in 2017.

The collaborative effort between ESA and USGS provides for public access and redistribution of global acquisitions of Sentinel-2 data at no cost, which allows users to download the MSI imagery from USGS access systems such as EarthExplorer, in addition to the ESA Sentinels Scientific Data Hub.

The MSI sensor acquires 13 spectral bands that are highly complementary to data acquired by the USGS Landsat 8 Operational Land Imager (OLI) and Landsat 7 Enhanced Thematic Mapper Plus (ETM+). The product options from USGS include a Full-Resolution Browse (FRB) image

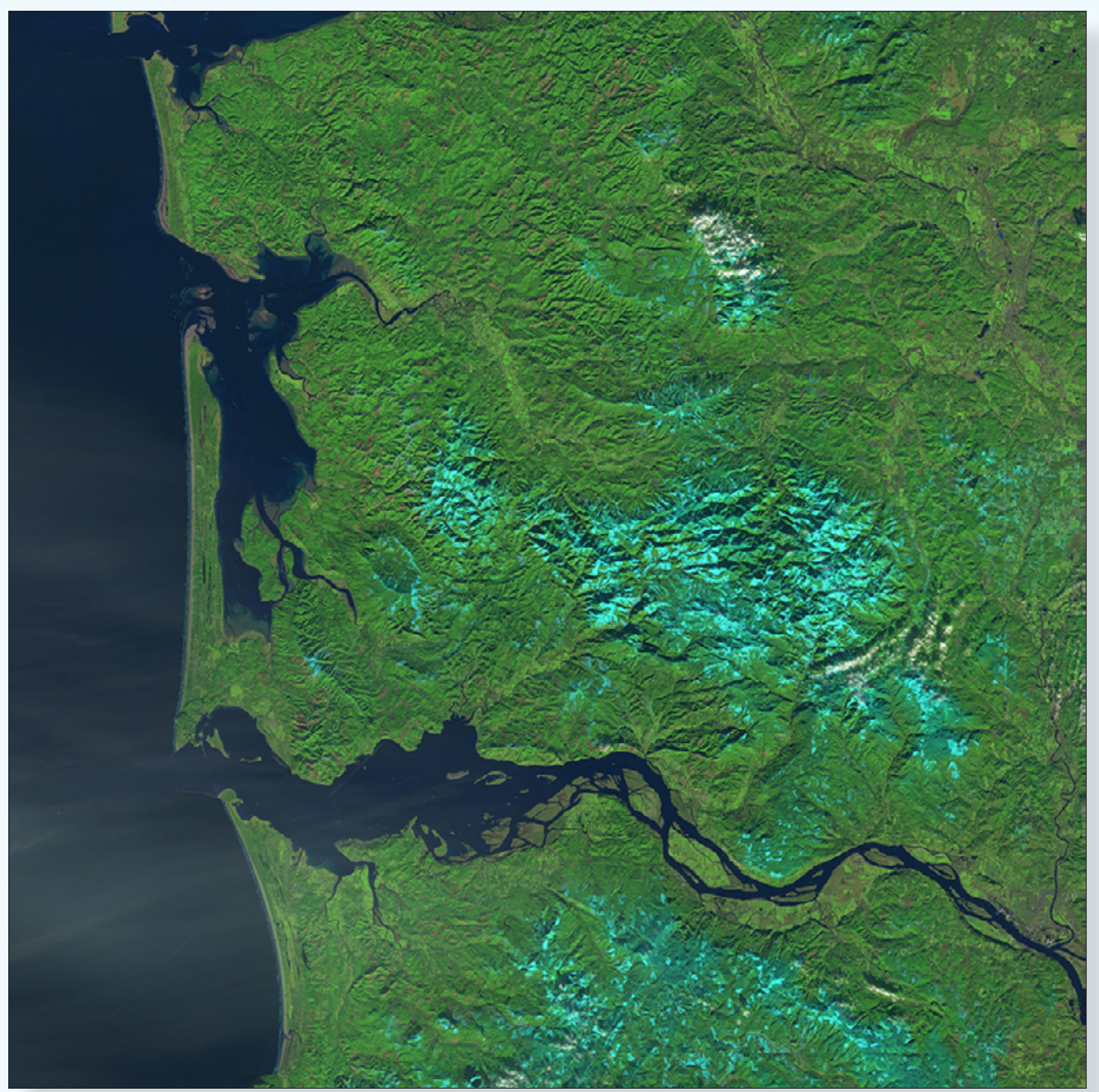

Figure 1. Sentinel-2A image acquired on December 7, 2016, over western Washington State and Oregon. This image is an example of the USGS-generated Full Resolution Browse (FRB) image, which is a simulated natural color composite image created from three selected bands $(11,8 \mathrm{~A}, 4)$ with a ground resolution of 20 meters. product generated by USGS (fig. 1), along with a 100-kilometer $(\mathrm{km})$ by 100-km tile-based Level-1C top-of-atmosphere (TOA) reflectance product that is very similar (but not identical) to the currently (2017) distributed ESA Level $1 \mathrm{C}$ product. 


\section{Data Characteristics}

Each Sentinel-2 satellite has a $290-\mathrm{km}$ orbital swath and a sun-synchronous polar orbit with a 10-day cycle. The Sentinel-2 satellite pair has an altitude of $786 \mathrm{~km}$ and provides 5-day repeat coverage. Combined with the 8-day coverage of Landsat 7-8, the revisit capability is reduced to 2-3 days at higher latitudes and 3-4 days toward the equator. The Sentinel-2 MSI uses a push-broom method of acquisition for its 13 spectral bands with a spatial resolution of 10 meters in the visible and one near infrared (VNIR) band, 20 meters in most near infrared (NIR) and short-wave infrared (SWIR) bands, and 60 meters in the coastal aerosol, water vapor, and cirrus bands. Level-1C processing applies radiometric and geometric corrections including orthorectification and spatial registration. Data are provided in $100 \mathrm{~km}$ by $100 \mathrm{~km}$ tiles with Universal Transverse Mercator (UTM) projection and World Geodetic System 1984 (WGS 84) datum. Figure 2 shows a visual comparison between MSI, OLI, and ETM+ spectral data.

\section{Access to Data}

Users can download the Sentinel-2 data at no cost through the USGS EarthExplorer, GloVis, and Sentinel2Look Viewer systems. The full-band data are provided as a compressed (ZIP) set of files in JPEG2000 format, packaged in the Standard Archive Format for Europe (SAFE) specification. The image bands can be used in processing software or by using ESA's open-source tools and plugins. A 20-meter three-band pre-composited image ("full-resolution browse") in GeoTIFF format is also available from USGS.

\section{U.S. Geological Survey Access and Distribution}

EarthExplorer: https://earthexplorer.usgs.gov/

Sentinel2Look Viewer: https://landsatlook.usgs.gov/ sentinel2

GloVis: http://glovis.usgs.gov/

\section{Additional Resources}

Sentinel-2 (USGS EROS): https://eros.usgs.gov/sentinel-2 Sentinel-2 (ESA): https://earth.esa.int/web/sentinel/ missions/sentinel-2

Copernicus Open Access Hub: https://scihub.copernicus. $\mathrm{eu} /$

Science Toolbox Exploitation Platform (SNAP Toolbox and Sen2Cor): http://step.esa.int/main/download/

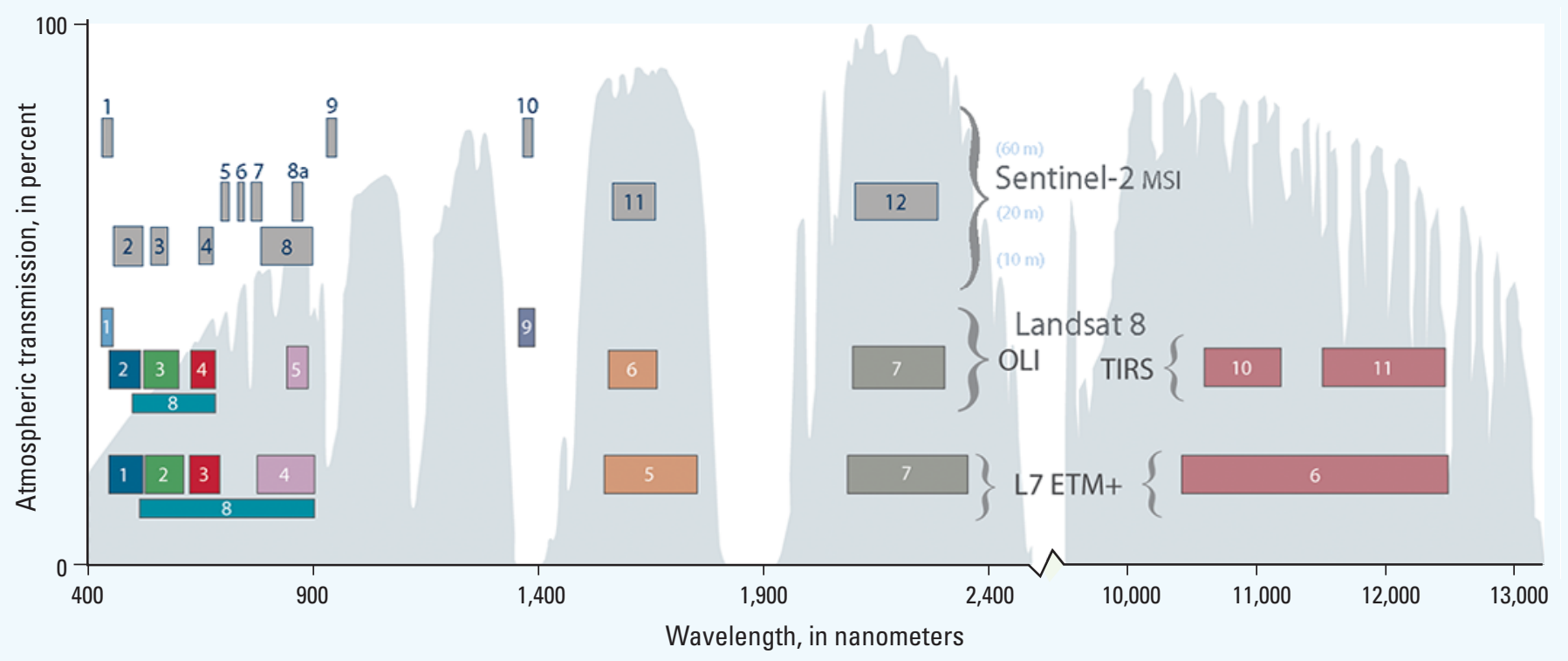

EXPLANATION

11 Number in colored rectangles are band numbers

Figure 2. Comparison of Landsat 7 and 8 bands with Sentinel-2 visibly shows where the bands overlap for the three sensors [MultiSpectral Instrument (MSI), Landsat 8 Operational Land Imager (OLI), Landsat 8 Thermal Infrared Sensor (TIRS) , Landsat 7 Enhanced Thematic Mapper Plus (L7 ETM+)].

\section{For additional information, contact:}

U.S. Geological Survey

Earth Resources Observation and Science (EROS) Center 47914 252nd Street, Sioux Falls, SD 57198-0001

Phone: 800-252-4547 or 605-594-6151

Email: custserv@usgs.gov

Website: https://eros.usgs.gov 